\title{
The effects of bilingualism on efficiency and lateralization of attentional networks*
}

\author{
ANNA MARZECOVÁ \\ Institute of Psychology, Jagiellonian University, \\ Krakow, Poland \\ DARIUSZ ASANOWICZ \\ Institute of Psychology, Jagiellonian University, \\ Krakow, Poland \\ L'UBA KRIVÁ \\ Military Rehabilitation Centre Slapy, Slapy, Czech \\ Republic \& Clinic of Addictology, General University \\ Hospital and Charles University in Prague, Prague, \\ Czech Republic \\ ZOFIA WODNIECKA \\ Institute of Psychology, Jagiellonian University, \\ Krakow, Poland
}

(Received: September 7, 2011; final revision received: July 18, 2012; accepted: July 31, 2012; first published online 9 October 2012)

\begin{abstract}
The present study investigated the impact of bilingualism on efficiency of alerting, orienting and executive attention by means of the Lateralized Attention Network Test (LANT). Young adult bilinguals who had been exposed to their second language before the age of four years showed a reduced conflict cost and a larger alerting effect in terms of response time (RT), while no difference between bilinguals and monolinguals was observed in overall RT. Bilinguals also outperformed monolinguals on accuracy in both conflict and non-conflict trials, though the effect in the latter condition was very small. Moreover, while a left visual field advantage for accuracy of conflict resolution was present in the monolingual group, bilinguals did not show the asymmetry. The findings suggest that bilingualism enhances the efficiency of executive network while reducing its lateralization. The larger alerting effect in bilinguals is hypothesized to be related to bilinguals' more efficient executive control, which may support processes of response anticipation or temporal orienting.
\end{abstract}

Keywords: bilingualism, attentional networks, hemispheric asymmetry, executive control, attention network test

\section{Introduction}

\section{Attentional functioning of bilinguals}

In recent years, there have been numerous reports showing beneficial effects of bilingualism on attentional functioning. In particular, the regular use of two (or more) languages has been found to enhance some aspects of executive attention, such as inhibition of irrelevant information or resolution of conflict among competing responses (Bialystok, Craik, Klein \& Viswanathan, 2004; Costa, Hernández, Costa-Faidella \& Sebastián-Gallés, 2009; Costa, Hernández \& Sebastián-Gallés, 2008; Luk, Anderson, Craik, Grady \& Bialystok, 2010; Treccani, Argyri, Sorace \& Sala, 2009). Still, several studies suggest that bilingualism may influence even broader range of

\footnotetext{
* We would like to thank Juan Lupiáñez, the anonymous reviewer, and the editor, David Green, for their many constructive comments and suggestions. We also acknowledge all participants. Anna Marzecová and Zofia Wodniecka were supported by a subsidy from the Foundation for Polish Science awarded to Zofia Wodniecka (FOCUS program).
}

attentional processes, such as monitoring of a task at hand (Costa et al., 2009), switching continuously between two tasks (Prior \& MacWhinney, 2010), inhibiting irrelevant spatial cues (Colzato, Bajo, van den Wildenberg, Paolieri, Nieuwenhuis, La Heij \& Hommel, 2008), or achieving and maintaining an alert state (Costa et al., 2008). The postulated enhancement of some attentional mechanisms may also result in negative side effects such as enlarged negative priming effect (Treccani et al., 2009) or more pronounced attentional blink (Colzato et al., 2008). Finally, several attempts failed to replicate the effects of bilingual advantage in executive control (Bialystok, 2005, Study 3; Colzato et al., 2008, Experiment 1; Costa et al., 2009, Experiment 1; Kousaie \& Phillips, 2011, 2012; Morton \& Harper, 2007). Taken together, there is a clear need to delineate the boundaries of bilingual impact on specific attentional processes (see Hernández, Costa, Fuentes, Vivas \& Sebastián-Gallés, 2010).

A theoretical framework that accounts for varieties of attentional functions was proposed by Posner and associates (Posner \& Boies, 1971; Posner \& Petersen, 1990; Posner \& Rothbart, 2007). The authors postulate

Address for correspondence:

Anna Marzecová, Institute of Psychology, Jagiellonian University, Al. Mickiewicza 3, 31-120 Kraków, Poland

anna.marzecova@gmail.com 
that three functionally and neuroanatomically separate attentional networks, namely alerting, orienting, and executive, subserve three different functions: achieving and maintaining an alert state, orienting to sensory or mental events, and inhibiting competitions or resolving response conflicts (Fan, McCandliss, Fossella, Flombaum \& Posner, 2005; Fan, McCandliss, Sommer, Raz \& Posner, 2002; Niogi, Mukherjee, Ghajar \& McCandliss, 2010; Westlye, Grydeland, Walhovd \& Fjell, 2010). The executive network is of particular importance for bilingual language processing. Bilingual individuals need to control two (or more) language systems by focusing attention on the language currently in use and inhibiting the interference from a non-relevant language (Abutalebi, Annoni, Zimine, Pegna, Seghier, Lee-Jahnke, Lazeyras, Cappa \& Khateb, 2008; van Heuven, Schriefers, Dijkstra \& Hagoort, 2008). The conflict caused by simultaneous activation of the languages is thought to be resolved by the domain-general control system (Abutalebi \& Green, 2007; Ye \& Zhou, 2009), which is subserved mainly by frontal brain areas, such as the prefrontal cortex (PFC) and the anterior cingulate cortex (ACC) - the main nodes of the executive network (Fan et al., 2005; Posner \& Rothbart, 2007). It has been proposed that a constant engagement of the executive network to resolve the language conflict provides intensive training, which boosts the network's efficiency (Bialystok, Craik, Green \& Gollan, 2009; Costa et al., 2008). However, it is not yet clear whether such bilingual experience may also influence the efficiency of other attentional networks.

A tool that allows for a reliable assessment of the efficiency of each of the three attentional functions independently is the Attention Network Test (ANT) developed by Fan et al. (2002; see Macleod, Lawrence, McConnell, Eskes, Klein \& Shore, 2010, for a detailed analysis of psychometric properties of the ANT). The ANT combines two classic experimental tasks, Posner's cueing task (Posner, 1980) and the flanker task (Eriksen \& Eriksen, 1974). More recently, Costa et al. (2008, 2009) conducted two ANT studies comparing the efficiency of attention in bilingual and monolingual young adults. With regard to the executive network, a mixed pattern of results was observed, suggesting that the hypothesized bilingual advantage in conflict resolution still needs to be clarified. Notably, Costa et al. (2008) found a larger alerting effect in bilinguals, as compared to monolinguals. However, subsequent study failed to replicate the effect (Costa et al., 2009), thus no firm conclusion on the functioning of the alerting network in bilinguals can be reached at present. In neither of the two referenced studies (Costa et al., 2008, 2009) effects of bilingualism on the orienting network were found, which contradicts previous evidence suggesting that bilingualism may affect orienting of attention (Colzato et al., 2008). To sum up, the findings from these two ANT studies show that further research is needed to elucidate the influence of bilingualism on the attentional networks.

\section{Functional hemispheric asymmetry in bilinguals}

Language-relevant neural systems are known to be in general strongly left lateralized, yet, it has been argued that bilinguals may have more bilateral organization of languages as compared to monolinguals (Hull \& Vaid, 2006; Peng \& Wang, 2010). A number of behavioral studies seem to support this notion (see Hull \& Vaid, 2006, 2007, for meta-analyses); however, Paradis (1995, 2003, 2008) criticized the methods implemented in these studies as lacking validity and reliability and even compared the differential hemispheric asymmetry observed in bilinguals to the declared sightings of the mythical Loch Ness monster. Nevertheless, several imaging and ERP studies of language processing have found a reduced hemispheric asymmetry in bilinguals (Dehaene, Dupoux, Mehler, Cohen, Paulesu, Perani, Van de Moortele, Lehéricy \& Le Bihan, 1997; Moreno, Bialystok, Wodniecka \& Alain, 2010; Park, BadzakovaTrajkov \& Waldie, 2012), thus corroborating previous behavioral evidence. Besides the demonstrations of altered inter-hemispheric organization of languagerelevant functions in bilinguals, it has also been shown that bilingualism appears to modulate within-hemispheric organization of domain-general executive functions (Garbin, Sanjuan, Forn, Bustamante, Rodriguez-Pujadas, Belloch, Hernández, Costa \& Ávila, 2010; Luk et al., 2010). We may, then, ask whether bilingualism may affect functional inter-hemispheric organization of nonlinguistic cognitive processes. To the best of our knowledge, so far, this issue has been addressed only in a single study. Hausmann, Durmusoglu, Yazgan \& Güntürkün (2004) compared bilinguals and monolinguals in a non-verbal lateralized face discrimination task. The results revealed a left visual field (LVF) advantage in monolinguals, corresponding to usually reported right hemisphere dominance in face processing (Dien, 2009; Gainotti, 2007), and no such asymmetry in the bilingual group. This might suggest that bilingualism indeed alters the inter-hemispheric organization of non-language processes. However, the underlying mechanisms of this effect have not been sufficiently accounted for.

We believe that while there appears to be no particular rationale to expect bilingual impact on cognitive functions, which are not related to the bilingual experience (e.g., face perception), it is nonetheless reasonable to suggest that bilingualism may influence inter-hemispheric organization of a neural network carrying out processes, which are specifically related to bilingual language functioning (e.g., executive network of attention). Importantly, it has been argued that lateralization of a cognitive process may be related to its efficiency in 
such way that better performance is associated with reduced asymmetry of the process (Boles \& Barth, 2011; Boles, Barth \& Merrill, 2008). According to this view, reduced lateralization of only those processes that are specifically enhanced by bilingualism should be expected. Given that bilinguals are considered to have advantage over monolinguals in attentional control (Bialystok et al., 2009), and that the human attentional system is known to be strongly lateralized (Heilman, 1995; Levy \& Wagner, 2011; Mesulam, 1999; Posner \& Petersen, 1990; Shulman $\&$ Corbetta, 2012), the issue of hypothesized reduced lateralization of non-linguistic cognitive processes in bilinguals might be disentangled by investigating the hemispheric asymmetry of attentional networks.

\section{Present study}

The objective of the present study was to compare the efficiency of the three attentional networks in bilinguals and monolinguals, and to investigate a potential effect of bilingualism on the lateralization of these networks. To meet the goals, we employed a lateralized variant of the Attention Network Test (LANT; Greene, Barnea, Herzberg, Rassis, Neta, Raz \& Zaidel, 2008) in the revised version proposed by Asanowicz, Marzecová, Jaśkowski \& Wolski (2012). The task has been shown to provide a measure of both the efficiency and the asymmetry of attentional networks, with reliability comparable to the original ANT (Fan et al., 2002). An additional value of the revised LANT is that it allows us to use error rate (ERR) as a second dependent variable, since the response time (RT) and ERR measurements yield similar and equally reliable results (Asanowicz et al., 2012). We expected that if bilinguals are indeed more efficient in conflict resolution per se, it would be reflected by faster response time and lower error rate specifically in the conflict condition, in which participants had to overcome the conflict elicited by the distracting flankers. The potential influence of bilingualism on alerting was of special interest, since equivocal results have been reported so far. No effects of bilingualism on the orienting network were expected. Finally, if degree of asymmetry is indeed related to performance in the way suggested by Boles and Barth (2011) and Boles et al. (2008), then bilinguals should exhibit reduced lateralization of processes in which they are more efficient than monolinguals.

\section{Methods}

\section{Participants}

Thirty-five right-handed young adults participated in the study (24 females and 11 males). The mean age was 21.8 years $(S D=3.2)$. All participants were university students or recent graduates; they had normal or corrected-to- normal vision, and no history of neurological disorders. They participated voluntarily and did not receive any gratification. The monolingual group $(N=17 ; 15$ females, 2 males; mean age: 20.0 years) comprised of individuals with minimal exposure to a second language (L2) in preschool age and with a minimal L2 exposure during compulsory language courses in school. All of them were native speakers of Polish and did not report to be functionally fluent in any other language. The bilingual participants $(N=18$; 9 females, 9 males; mean age: 23.5 years) were recruited on the basis of the age of their exposure to L2; only individuals who were exposed to L2 in their preschool age were selected. The group consisted of speakers of different sets of languages who were functionally fluent in Slovak and Czech $(N=10)$, Slovak and Polish $(N=1)$, Slovak and Russian $(N=1)$, Polish and English $(N=2)$, Polish and Ukrainian $(N=1)$, Polish and Russian $(N=2)$, or Belarusian and Russian $(N=1)$. All bilinguals were exposed to their L2 before or at the age of four (11 participants reported to be exposed to their L2 from birth). The majority of participants also reported knowledge of a third language (L3). Table 1 shows participants' self-rated proficiency and the percentage of their daily use of each language. Bilinguals rated their knowledge of L1 higher than L2 and although most of them lived in the L2 context (studying or working), they reported more frequent daily use of L1 than L2.

\section{Materials and stimuli}

\section{Language History and Background Questionnaire}

Information on language use and skills was collected using a questionnaire developed based on the questionnaire of Li, Sepanski \& Zhao (2006). It included questions on age of exposure to languages, intensity of language use, as well as self-evaluation scales to assess participants' language skills in comprehension, reading, speaking, and writing. Proficiency scores were assessed by means of a seven-point scale $(1=$ very poor, $2=$ poor, $3=$ fair, $4=$ functional, $5=$ good, $6=$ very good, $7=$ native-like). ${ }^{1}$

\footnotetext{
1 Bilingual participants also reported knowledge and use of a third language (except for one participant; see Table 1), but the level of proficiency and extent of usage of the third language differed between them. To test whether these variables are related to the efficiency of attentional networks, we calculated Pearson's correlations of the networks' scores with the self-rated proficiency score, and the percentage of daily use of the third language $(N=18$, the speaker of two languages scored 0 in both proficiency and percentage of daily use). The correlations were small and far from significant, except for a stronger but also not significant correlation between percentage of daily use of $\mathrm{L} 3$ and the alerting index $(r=.39, p=.12)$. Hence, no link between L3 and attentional efficiency was observed. Additionally, we compared the sample of multilingual participants from the current study with the sample of early bilinguals from Tao et al.'s (2011) experiment, to further investigate potential effects
} 
Table 1. Characteristics of language use in bilingual group: the age of exposure to the language, self-rated proficiency in four aspects of language use and percentage of daily use.

\begin{tabular}{llcr}
\hline \hline & L1 & L2 & \multicolumn{1}{c}{ L3 $^{\mathrm{a}}$} \\
\hline Age of exposure (in years) & 0 & $0.97(1.44)$ & $7.50(4.59)$ \\
Proficiency of understanding (1-7) & $7.00(0.0)$ & $6.72(0.54)$ & $5.82(1.01)$ \\
Proficiency of reading (1-7) & $7.00(0.0)$ & $6.78(0.55)$ & $6.18(0.95)$ \\
Proficiency of speaking (1-7) & $6.94(0.24)$ & $6.06(0.80)$ & $5.18(1.29)$ \\
Proficiency of writing (1-7) & $6.78(0.55)$ & $5.77(0.97)$ & $5.41(1.23)$ \\
Percentage of use $(0-100 \%)^{\mathrm{b}}$ & $53.56(28.31)$ & $30.94(28.93)$ & $14.3212 .9)$ \\
\hline \hline
\end{tabular}

${ }^{a}$ Except for one participant, all bilinguals reported knowledge of at least three languages (for 12 participants the L3 was English, for 4 participants it was another Slavic language, and for 1 participant it was Spanish). Sixteen participants also reported basic knowledge of L4 (acquired mostly in language courses), but the proficiency of L4 was very low and the usage infrequent (only 11 participants reported some daily use of L4).

${ }^{\mathrm{b}}$ Participants were asked to assess the percentage of daily use for every language, which would sum up to $100 \%$. Eleven participants used also L4 for $3.2 \%$ (SD 4.3$)$ of time.

\section{Raven's Advanced Progressive Matrices}

A shortened version of Raven's Advanced Progressive Matrices test (sRAPM; Raven, Raven \& Court, 1998) was used to measure participants' fluid intelligence. Participants were given twenty minutes to complete 18 test items that increased in difficulty. The items used in the shortened version were the odd-numbered items from the complete 36-item RAPM test. ${ }^{2}$

of L3 use on alerting and conflict resolution, i.e., the effects, in which bilingual advantage was observed in the present study. No significant differences between experiments were found in both the alerting effect $\left(F(1,52)=2.49, p=.12, \eta_{p}^{2}=.04\right)$, and the conflict effect $(F<1.0)$. The results therefore suggest that multilingualism, as compared to bilingualism, did not bring about any additional benefits for the efficiency of attentional networks. However, the comparison between the two studies should be interpreted with caution due to some differences in the LANT procedure. For example, in the Tao et al.'s study, the eccentricity of the stimuli was smaller $\left(2.2^{\circ}\right.$ between the target and the fixation, compared to $3.3^{\circ}$ in the present study), which made the task slightly easier perceptually; and the number of trials was half smaller than in the current experiment. Therefore, potential benefits of multilingualism should be more systematically addressed in future studies.

2 In the present study, intelligence level was measured by the shortened, split-half version of the Raven's Advanced Progressive Matrices, which is often used in experimental studies (see Engle \& Kane, 2004; Kane, Hambrick, Tuholski, Wilhelm, Payne \& Engle, 2004). (For instance, in Kane's et al. (2004) model, the intelligence score calculated from the shortened version of the test highly correlates with general fluid intelligence $(r=.76)$. This correlation may be considered as high, since the test-retest correlation for the full version of Raven's matrices usually oscillates around the $r=.8$ level.) The mean Raven's score in the bilingual group was 14.0 points $(S D=2.5)$, whereas the mean for monolinguals was 12.0 points $(S D=2.0)$. The twopoint difference was statistically significant $(t(33)=2.7, p=.009)$. To rule out the possibility that the observed between group effects were related to the differences in intelligence scores, we calculated correlations between the sRAMP score and the indexes of conflict resolution. The correlations were low and not significant (for RT: $r=$ $-.24, p=.16$, and for ERR: $r=-.06, p=.7$ ). In addition, we

\section{Lateralized Attention Network Test}

The revised Lateralized Attention Network Test (LANT; Asanowicz et al., 2012) was used to measure the efficiency and lateralization of three attentional networks: alerting, orienting, and executive. (In line with the suggestion by Boles \& Barth (2011) that the best approach to reveal relationship between efficiency and lateralization of a given process is to use the same task to measure both variables.) The task is illustrated in Figure 1. Each trial of the task began with a fixation point, presented at the center of a computer screen. The fixation point remained displayed during the whole trial. The target stimulus was an arrow pointing either up or down, presented in the left or right visual field (50/50\%). In each trial, the target arrow was flanked by four additional arrows pointing either in the same (congruent flankers) or in the opposite directions (incongruent flankers). Participants were asked to identify in which direction the target (middle) arrow was pointing. The speed and accuracy of responses were measured. The incongruent condition involved conflict between two competing reactions, thus the difference between congruent and incongruent conditions indicated a cost of conflict resolution, which is an index of the executive network's efficiency (Fan et al., 2002). In addition, four cue conditions were used. Targets appeared without any cue, or were preceded by one of three types of visual cues: a center cue, presented in the same location as the fixation cross; a spatial valid cue presented in the target location, and a spatial invalid cue, which appeared

performed all analyses reported in the present paper as ANCOVAs with sRAMP score as a covariate. The between-subject effect of intelligence was insignificant both for the $\mathrm{RT}(F(1,32)=1.4, p=.23$, $\left.\eta_{p}^{2}=.04\right)$ and for the $\operatorname{ERR}\left(F(1,32)=0.02, p=.87, \eta_{p}^{2}=.001\right)$. All the main effects and interactions that were found significant by ANOVA remained significant when controlling for the differences in intelligence. This suggests that the differences in the intelligence between the two groups did not impact the result patterns in the LANT. 


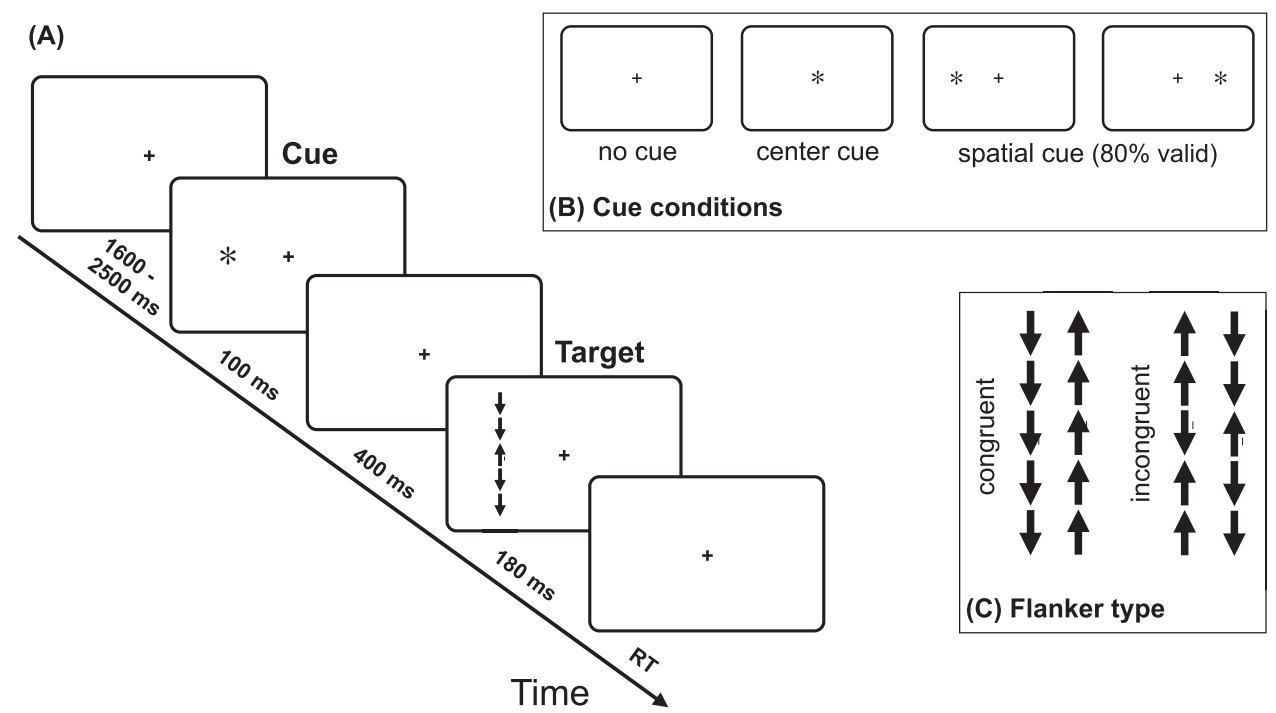

Figure 1. Experimental procedure: an example of the sequence of events for a trial with the valid spatial cue and the incongruent flankers (A); the cue conditions (B); the two types of flankers (C).

in the location opposite to the following target (in $20 \%$ of spatial cue trials). The center cue alerted participants by signaling when the target would occur, thus, the efficiency of the alerting network was measured by subtracting reaction time or accuracy in the center cue condition from the no-cue condition (Fan et al., 2005). The spatial valid cue indicated where the target would occur, thus, subtracting the spatial valid cue condition from the invalid cue condition provided an index of orienting (Fan, Gu, Guise, Liu, Fossella, Wang \& Posner, 2009; Posner, 1980). Additionally, by subtracting the spatial valid cue condition from the center cue condition an index of orienting benefit was obtained, whereas by subtracting the center cue condition from the spatial invalid cue condition efficiency of reorienting of attention was measured (or orienting cost, Greene et al., 2008).

We characterize the visual displays in terms of their length ( $\mathrm{mm}$ ) and subtended visual angle (in degrees). The target central arrow and the flankers were each $6 \mathrm{~mm}$ $\left(0.57^{\circ}\right)$ long. The length of all five arrows in the display was $32 \mathrm{~mm}\left(3.0^{\circ}\right)$. They were displayed $35 \mathrm{~mm}\left(3.3^{\circ}\right)$ to the left or right of the fixation cross, which was $3 \mathrm{~mm}$ $\left(0.3^{\circ}\right)$ in width. An asterisk $\left(5 \mathrm{~mm}, 0.47^{\circ}\right.$ diameter $)$ was used as a cue and it was displayed either in the position of the fixation cross or laterally at the same position as the target stimuli. The stimuli were presented via DMDX software (Forster \& Forster, 2003). The fixation period of random variable duration (1600-2500 ms) was followed by a cue presented for $100 \mathrm{~ms}$. After an offset of the cue an inter-stimulus interval (400 ms) was displayed, followed by the target and flankers presented for $180 \mathrm{~ms}$. As in the previous ANT (Fan et al., 2002) and LANT studies (Greene et al., 2008), the stimulus onset asynchrony (SOA) was $500 \mathrm{~ms}$ in all trials. In the no cue condition the target appeared immediately after the fixation period. A new trial began immediately after participant's response or after $2000 \mathrm{~ms}$ if the participant did not respond.

\section{Procedure}

The LANT began with a practice session, in which participants completed two blocks of the task, each consisting of 16 trials, and received feedback on their accuracy after each response. The practice session was followed by 576 experimental trials, divided into 4 blocks of 144 trials each. In each block, $50 \%$ of the trials were congruent and 50\% were incongruent. On 128 trials no cue was presented. The alerting center cue was presented on another 128 trials. On the remaining trials, targets were preceded by spatial cues; $80 \%$ of these were valid (256 trials) and 20\% were invalid (64 trials). To ensure sufficient number of trials in the invalid spatial cue condition, the total number of trials with spatial cues was 320. The task lasted up to one hour. In between blocks participants were allowed to have short breaks to rest their eyes. Participants were asked to keep head and body still, to fixate on the cross in the screen, and to respond to targets as quickly and accurately as possible. Responses were made by pressing keys on a computer mouse. To make responding easier and more natural, spatial compatibility of the response pattern and the direction of the arrows was ensured. The mouse was placed at midline, parallel to the screen. In this way the right and left buttons were positioned up and down. Participants were asked to press the upper button for the up-pointing targets, and the lower button for the down-pointing ones. When participants used their right hands, they used their middle finger to press the right button (i.e., the "upper" button) for the 
Table 2. Response times of correct responses and error rates (means and SDs) for all conditions (VF $=$ visual field).

\begin{tabular}{|c|c|c|c|c|c|c|c|c|c|c|}
\hline \multirow[b]{3}{*}{ Cue condition } & \multirow[b]{3}{*}{ Flanker type } & \multirow[b]{3}{*}{ VF } & \multicolumn{4}{|c|}{ Response time (ms) } & \multicolumn{4}{|c|}{ Error rate $(\%)$} \\
\hline & & & \multicolumn{2}{|c|}{ Monolinguals } & \multicolumn{2}{|c|}{ Bilinguals } & \multicolumn{2}{|c|}{ Monolinguals } & \multicolumn{2}{|c|}{ Bilinguals } \\
\hline & & & Mean & $S D$ & Mean & $S D$ & Mean & $S D$ & Mean & $S D$ \\
\hline \multirow[t]{4}{*}{ No cue } & \multirow[t]{2}{*}{ Congruent } & Left & 631 & 46 & 634 & 73 & 2.0 & 4.0 & 2.8 & 3.4 \\
\hline & & Right & 631 & 49 & 638 & 67 & 3.1 & 3.7 & 3.8 & 4.6 \\
\hline & \multirow[t]{2}{*}{ Incongruent } & Left & 730 & 52 & 720 & 62 & 33.5 & 17.9 & 24.3 & 12.2 \\
\hline & & Right & 731 & 58 & 725 & 70 & 44.5 & 25.2 & 26.0 & 20.9 \\
\hline \multirow[t]{4}{*}{ Valid spatial } & \multirow[t]{2}{*}{ Congruent } & Left & 516 & 54 & 510 & 67 & 1.0 & 1.7 & 0.7 & 1.0 \\
\hline & & Right & 524 & 60 & 517 & 65 & 1.6 & 1.6 & 0.6 & 0.8 \\
\hline & \multirow[t]{2}{*}{ Incongruent } & Left & 610 & 80 & 580 & 67 & 10.8 & 12.7 & 7.7 & 8.3 \\
\hline & & Right & 630 & 80 & 583 & 72 & 13.1 & 15.6 & 5.6 & 6.2 \\
\hline \multirow[t]{4}{*}{ Invalid spatial } & \multirow[t]{2}{*}{ Congruent } & Left & 656 & 64 & 672 & 94 & 12.9 & 11.6 & 6.6 & 10.8 \\
\hline & & Right & 662 & 52 & 684 & 92 & 14.0 & 10.7 & 7.3 & 8.4 \\
\hline & \multirow[t]{2}{*}{ Incongruent } & Left & 742 & 76 & 732 & 74 & 32.7 & 21.9 & 31.6 & 21.6 \\
\hline & & Right & 729 & 86 & 735 & 92 & 48.5 & 20.6 & 34.7 & 18.5 \\
\hline \multirow[t]{4}{*}{ Center } & \multirow[t]{2}{*}{ Congruent } & Left & 592 & 53 & 584 & 71 & 0.7 & 1.4 & 0.7 & 1.7 \\
\hline & & Right & 595 & 55 & 590 & 75 & 2.4 & 2.6 & 1.4 & 1.9 \\
\hline & \multirow[t]{2}{*}{ Incongruent } & Left & 701 & 56 & 673 & 62 & 19.3 & 19.0 & 11.8 & 12.2 \\
\hline & & Right & 707 & 71 & 676 & 69 & 24.5 & 19.6 & 12.2 & 9.9 \\
\hline
\end{tabular}

targets pointing up and their index fingers to press the left (i.e., "lower") button for the targets pointing down. For the left hand, the mouse was turned by 180 degrees and the response mapping was reversed, i.e., the right button became the down key, and the left button became the upper key. For each participant, response hand alternated between blocks. The trials were presented in a new random order for each participant. After the LANT was finished, participants were asked to complete a shortened version of the Raven's Advanced Progressive Matrices test. The Language History and Background Questionnaire was completed prior to the experimental session.

\section{Results}

Data from trials with response times (RT) faster than 200 $\mathrm{ms}$, slower than $1200 \mathrm{~ms}$ ( $1.2 \%$ of correct responses), and error trials (13.7\% of all trials) were excluded from the RT analysis. Table 2 shows mean RT and ERR in each experimental condition for both groups of participants.

\section{Overall RT and ERR}

Overall mean RT for correct responses was $645 \mathrm{~ms}$ $(S D=58)$. Overall mean error rate $(E R R)$ was $13.8 \%$ $(S D=7.1)$. The overall ERR was notably higher than in the ANT and the original LANT studies (Fan et al., 2002; Greene et al., 2008) because the current version of the task put more demands on attention due to increased retinal eccentricity of the stimuli (from the original $1.1^{\circ}$ to $3.3^{\circ}$ ). We assumed that when visual acuity decreases, discrimination of the target requires more attention to boost the apparent stimulus contrast and clarity (see Carrasco, Ling \& Read, 2004). The aim of this modification was to obtain higher reliability in measurement of attentional asymmetries (see Asanowicz et al., 2012, for more details). Unlike in previous studies on bilinguals with the ANT (Costa et al., 2008, 2009), there was no significant difference in the overall mean RT between the two groups $\left(F(1,33)=.18, p=.68, \eta_{p}^{2}=.01\right)$, while bilinguals were generally more accurate $(11.1 \%$ of ERR) than monolinguals (16.5\% of ERR) across all LANT conditions $\left(F(1,33)=5.84, p=.021, \eta_{p}^{2}=.021\right)$.

\section{Alerting network}

The alerting index was computed as the difference between no cue and center cue conditions (Fan et al., 2005). The center cue accelerated response time, which was on average $40 \mathrm{~ms}$ faster when the cue was presented $\left(F(1,33)=173.74, p<.0001, \eta_{p}^{2}=.84\right)$. The alerting effect was significantly larger in the bilingual group than in the monolingual group (48 vs. $33 \mathrm{~ms} ; F(1,33)=7.08$, $\left.p=.012, \eta_{p}^{2}=.18\right)$, which replicated the previous finding by Costa et al. (2008). Importantly, the effect was brought about by the advantage of bilinguals in the center cue 
condition, since there was no difference between groups in the no cue condition (see Figure 3). The overall alerting effect was significant also for ERR, showing that participants made $8 \%$ fewer errors in the center cue condition than in the no cue condition $(F(1,33)=68.47$, $\left.p<.0001, \eta_{p}^{2}=.67\right)$, but there was no difference between groups $(F<1.0)$. For both RT and ERR measures, no significant interactions were obtained between the alerting effect and VF, and between the alerting effect, VF and group (all $F \mathrm{~s}<1.0$, except for the alerting $\times \mathrm{VF}$ interaction in ERR, where $F=1.6$ ).

\section{Orienting network}

The orienting index was calculated by subtracting the valid spatial cue condition from the invalid spatial cue condition (see Fan et al., 2009; Posner, 1980). The effect was $143 \mathrm{~ms}$ for RT $(F(1,33)=150.16, p<.0001$, $\left.\eta_{p}^{2}=.82\right)$ and $18.3 \%$ for $\operatorname{ERR}(F(1,33)=84.20$, $\left.p<.0001, \eta_{p}^{2}=.72\right)$. A significant interaction between cue and VF was observed for ERR $(F(1,33)=7.41$, $\left.p=.010, \eta_{p}^{2}=.18\right)$, which revealed, similarly to our previous LANT study (Asanowicz et al., 2012), a LVF advantage in responses to the invalidly cued targets $\left(\mathrm{RVF}-\mathrm{LVF}=5 \%, \quad\left(F(1,33)=7.32, p=.011, \eta_{p}^{2}=.18\right)\right.$ and no VF asymmetry in the valid cue condition $(\mathrm{RVF}-\mathrm{LVF}=0.1 \%, F<1.0)$. There were no significant between-group differences in the orienting effects, for both RT $\left(F(1,33)=1.70, p=.20, \eta_{p}^{2}=.05\right)$ and ERR $\left(F(1,33)=1.00, p=.32, \eta_{p}^{2}=.03\right)$. A three-way interaction between cue, VF and group was also insignificant, which suggests that the LVF advantage for the invalidly cued targets was not influenced by bilingualism.

To explore the orienting effect in detail, we calculated two additional indexes: an index of orienting benefit (center cue MINUs valid spatial cue, Fan et al., 2002), and an index or reorienting (or orienting cost; invalid cue MINUS center cue, Greene et al., 2008). The orienting benefit effect yielded $82 \mathrm{~ms}$ for RT $(F(1,33)=208.82$, $\left.p<.0001, \eta_{p}^{2}=.86\right)$, and $4 \%$ for $\operatorname{ERR}(F(1,33)=19.88$, $\left.p<.0001, \eta_{p}^{2}=.37\right)$. No interactions of the orienting benefit effect with VF and group were observed, either for RT or for ERR. The analysis of the reorienting effect revealed that responses in the invalid spatial cue condition were $62 \mathrm{~ms}$ longer $(F(1,33)=79.93, p<.0001$, $\left.\eta_{p}^{2}=.71\right)$ and $14 \%$ less accurate $(F(1,33)=58.91$, $\left.p<.0001, \eta_{p}^{2}=.64\right)$ than in the center cue condition. Interestingly, the cue by group interaction in RT was significant $\left(F(1,33)=3.54, p=.070, \eta_{p}^{2}=.10\right)$. However, this effect was driven by the bilingual advantage in the center (i.e., alerting) cue condition that was reported above. The difference between groups in the invalid spatial cue condition yielded only $8 \mathrm{~ms}$ and was not significant $(F<1.0)$. For the ERR measurement, the cue by group interaction was not significant $(F<1.0)$. The cue $\times \mathrm{VF} \times$ group interaction was not significant for both RT and ERR (both $F \mathrm{~s}<1.0$ ).

\section{Executive network}

The index of conflict cost reflects the efficiency of executive network in the resolution of cognitive conflict and is obtained by subtracting the congruent flanker condition from the incongruent flanker condition. The effect was $85 \mathrm{~ms}$ for RT $(F(1,33)=407.68, p<.0001$, $\left.\eta_{p}^{2}=.92\right)$ and $20 \%$ for $\operatorname{ERR}(F(1,33)=92.79, p<.0001$, $\left.\eta_{p}^{2}=.74\right)$. The ERR conflict effect was $4 \%$ larger for LVF targets, as revealed by the flanker type $\times \mathrm{VF}$ interaction $\left(F(1,33)=5.67, p=.023, \eta_{p}^{2}=.14\right)$, and the asymmetry was greater in the incongruent condition $(\mathrm{RVF}-\mathrm{LVF}=5 \%)$ than in the congruent condition $(\mathrm{RVF}-\mathrm{LVF}=0.8 \%)$. In RT measurement, the conflict effect was significantly smaller for bilinguals than for monolinguals (74 vs. $96 \mathrm{~ms}$; interaction flanker type $\times$ group: $F(1,33)=6.72, p=.014, \eta_{p}^{2}=.17$; see Figures 2 and 4). Bilinguals also enjoyed $7 \%$ advantage in the ERR conflict effect, although this effect was only marginally significant $(F(1,33)=3.17, p=.084$, $\eta_{p}^{2}=.09$; see Figures 2 and 4 ). As reported above (see section: Overall RT and ERR), bilinguals exhibited a general advantage in ERR. In other words, monolinguals committed more errors not only in the conflict trials, but also in the non-conflict trials, and this might have lead to only marginally significant group difference for the index of conflict cost.

The two groups also showed a differential lateralization of the conflict effect in the ERR. We found significant interactions between VF and group for the ERR data collapsed across congruent and incongruent flanker conditions $\left(F(1,33)=6.14, p=.02, \eta_{p}^{2}=.16\right)$ and between flanker type, VF and group $(F(1,33)=5.19$, $\left.p=.03, \eta_{p}^{2}=.14\right)$. As expected, monolinguals showed a clear LVF advantage in the incongruent condition $(t(16)=3.72, p=.001)$, and no asymmetry in the congruent flanker condition $(t(16)=1.44, p=.17)$, whereas in the bilingual group no asymmetry was observed for either of the flanker conditions (both $t \mathrm{~s}<1.0$; see Figure 5). When analyzed separately for each flanker condition, the $\mathrm{VF} \times$ group interaction was significant for the incongruent flankers $(F(1,33)=6.47, p=.016$, $\eta_{p}^{2}=.16$ ), and non-significant for the congruent flankers $(F<1.0$; see Figure 5).

\section{Interactions between attentional networks}

A $4 \times 2 \times 2 \times 2$ mixed ANOVA including all conditions together showed that the conflict effect was significantly modulated by cues, in both RT $(F(3,99)=10.41$, $\left.p<.001, \eta_{p}^{2}=.24\right)$ and $\operatorname{ERR}(F(3,99)=28.55, p<.0001$, 


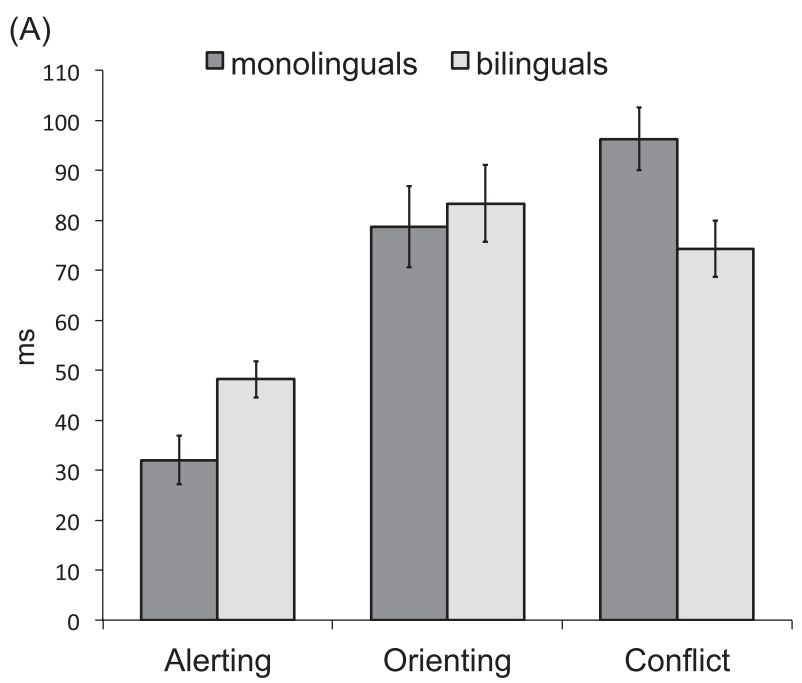

(B)

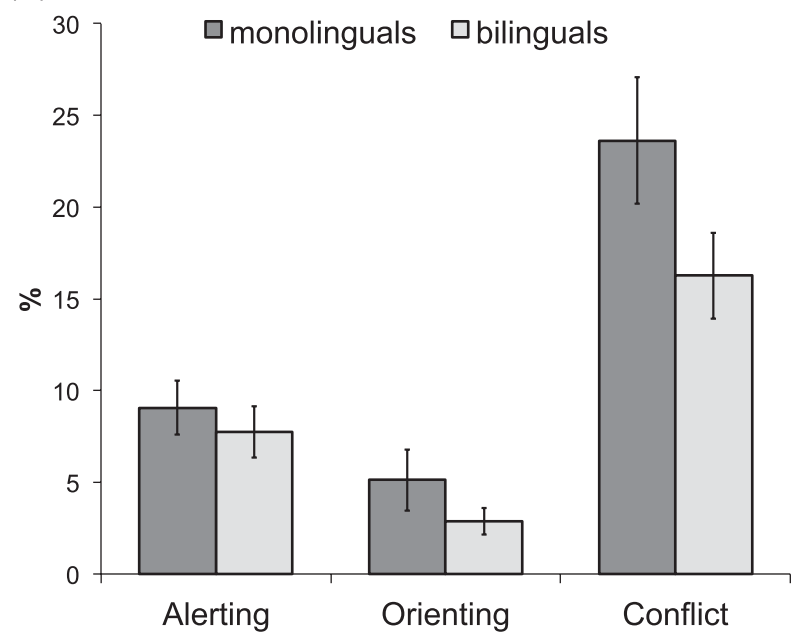

Figure 2. Attentional network scores in terms of RT (A) and ERR (B).

$\left.\eta_{p}^{2}=.46\right)$. Therefore, to investigate interactions between conflict and alerting, and between conflict and orienting independently (see Callejas, Lupiáñez \& Tudela, 2004), we conducted two separate $2 \times 2 \times 2$ ANOVAs with cue (no cue and center cue for alerting effect; valid spatial cue and invalid spatial cue for orienting effect), flanker type (congruent, incongruent), and group (monolingual, bilingual) as independent variables.

\section{Conflict $x$ alerting}

The interaction between conflict and alerting was not significant in $\operatorname{RT}\left(F(1,33)=2.11, p=.15, \eta_{p}^{2}=.06\right)$, but in the ERR measurement the conflict effect was significantly smaller when the center cue was presented, compared to when the cue was absent $(F(1,33)=37.92$, $\left.p<.0001, \eta_{p}^{2}=.53\right)$. This result corroborates our previous data obtained with the LANT (Asanowicz et al., 2012).

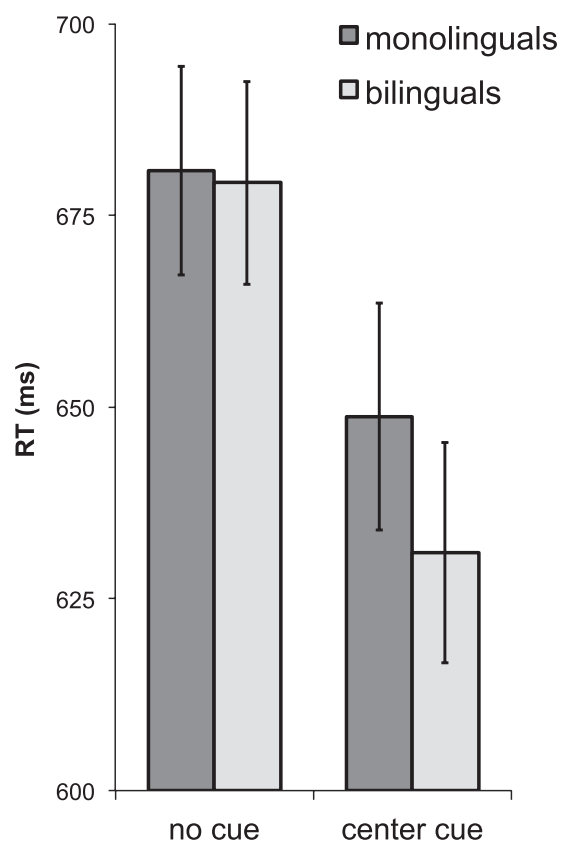

Figure 3. Alerting effect: cue condition by group interaction.

Importantly, the interaction between cue, flanker and group was significant neither for RT $(F(1,33)=1.55$, $\left.p=.22, \eta_{p}^{2}=.04\right)$ nor for $\operatorname{ERR}(F(1,33)=1.37, p=.25$, $\left.\eta_{p}^{2}=.04\right)$.

\section{Conflict $\mathrm{x}$ orienting}

Orienting cues modulated the magnitude of conflict effect in both RT $\left(F(1,33)=5.55, p=.025, \eta_{p}^{2}=.14\right)$ and ERR $\left(F(1,33)=42.31, p<.0001, \eta_{p}^{2}=.56\right)$. Interestingly, in the RT analysis the conflict effect was $19 \mathrm{~ms}$ greater in the valid cue than in the invalid cue condition, while in the ERR the pattern was reversed, i.e., the cost of conflict was smaller in the valid cue than in the invalid cue condition. On one hand, these results might suggest a trade-off between accuracy and speed of responses. Alternatively, the difference may be caused by a floor effect in ERR measurement. As the RT data show, the valid cue speeded up response time in both congruent and incongruent conditions, but this facilitative effect was slightly larger in the congruent condition. In the accuracy measurement, when the valid cue was presented, accuracy in the congruent condition was at ceiling (ERR was only $1 \%$ ). More importantly, the cue $\times$ flanker $\times$ group interaction was significant neither for RT nor for ERR (both $F \mathrm{~s}<1.0$ ), suggesting that bilingualism did not modulate the relation between orienting and executive networks. 

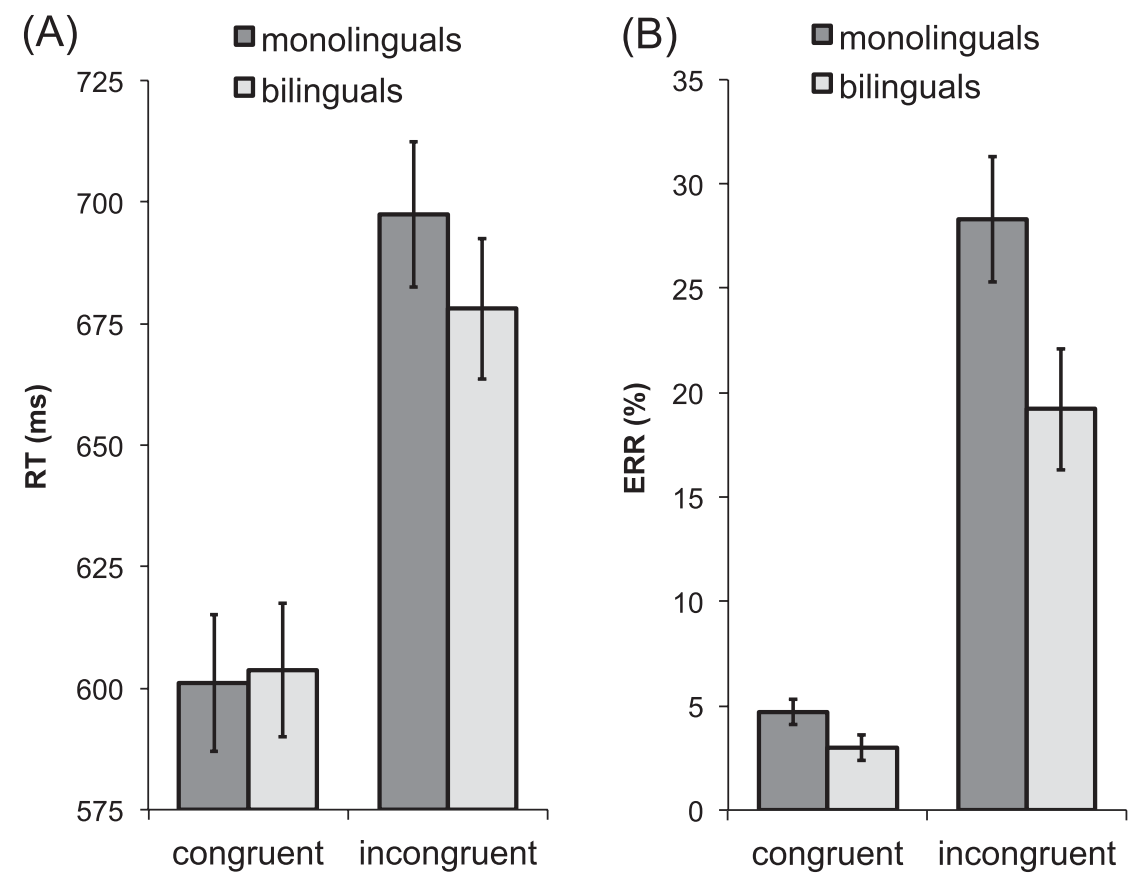

Figure 4. Interaction flanker type $\times$ group for RT (A) and ERR (B).

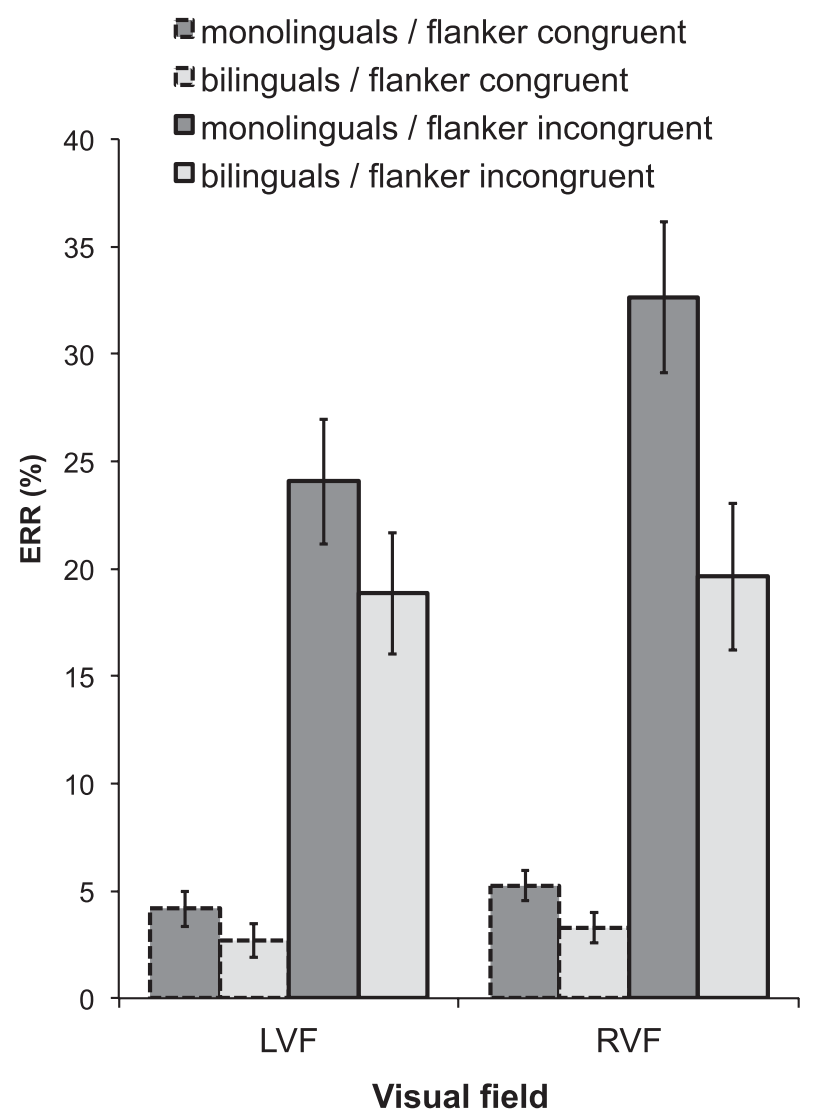

Figure 5. Error rates in LVF and RVF by flanker condition for monolinguals and bilinguals.

\section{Discussion}

The first aim of the present study was to compare the efficiency of attentional networks in bilingual and monolingual young adults. Previous research has brought equivocal results showing the effects of bilingualism on alerting and executive network (Costa et al., 2008), as well as the lack of them (Costa et al., 2009). The second aim of our study was to investigate the issue of reduced hemispheric asymmetry in bilinguals. We implemented the Lateralized Attention Network Test (Asanowicz et al., 2012) that allowed us to measure individual differences in both efficiency and lateralization of attentional networks. The overall pattern of alerting, orienting, and conflict effects was similar to the earlier studies using the ANT (Fan et al., 2002; see also MacLeod et al., 2010, for meta-analysis) and the LANT (Asanowicz et al., 2012), indicating that the task provides a reliable assessment of the networks' efficiency. Thus, the investigation of differences between bilinguals and monolinguals seems to be well grounded. Three main findings of the present study were: bilingual advantage in conflict resolution, larger alerting effect in bilinguals, and the reduced VF asymmetry of the conflict effect in bilinguals.

\section{Bilingualism and executive control}

Assuming that bilingual experience provides a specific form of attention training, which enhances the efficiency 
of executive control (Abutalebi \& Green, 2007; Bialystok, 2005; Green, 1998), we expected bilinguals to be more effective than monolinguals in conflict resolution. In line with the hypothesis, bilinguals were both faster and more accurate in the conflict condition, which requires a suppression of interference from incongruent flankers. The result confirms previous evidence from the ANT (Costa et al., 2008) and other conflict tasks, such as Simon task (Bialystok et al., 2004) and Stroop task (Hernández et al., 2010). However, unlike in most of those studies, in the current experiment the bilingual advantage was not limited to RT, but was also observed in ERR. More importantly, the advantage of bilinguals in response time was observed only for the conflict trials, whereas a number of previous studies reported bilingual advantage in overall RT, i.e., pooled across all, conflict and non-conflict conditions (Bialystok et al., 2004; Bialystok, Martin \& Viswanathan, 2005; Costa et al., 2008). Moreover, as Hilchey \& Klein's (2011) review showed, in many studies the bilingual advantage in conflict effect was clearly absent, while bilingual advantage on overall RT was still present. Such a pattern of results led Costa et al. (2009) to suggest that the bilingual advantage in conflict tasks may be due to the enhanced efficiency of a monitoring system - a higher-level mechanism that allows individuals to detect the presence of conflict and evaluates the need of its resolution (pp. 141-142). The authors proposed two hypotheses of how the monitoring and conflict resolution systems may be affected by bilingualism. According to the first one, bilingualism influences both monitoring and conflict resolution, probably in a relatively independent way. The second hypothesis suggests that both effects, i.e., the smaller cost of conflict and the advantage on overall RT, reflect an enhancement of the same attentional component, namely the monitoring system. According to Costa et al. (2009, p. 144), this system in some cases "may speed up performance for congruent trials to a lesser extent than for incongruent trials, leading not only to overall faster RTs, but also to a reduction in the magnitude of the conflict effect". Under this view, a finding of bilingual advantage in either overall RT or conflict effect depends on the extent of engagement of monitoring system in a given experimental procedure. For instance, if a procedure with $50 / 50 \%$ proportion of congruent to incongruent trials is used and the trials are presented in a mixed and random order, the monitoring system will be involved to a great extent, thus a bilingual advantage should be observed. However, if the congruent and incongruent trials are blocked and present in separate series, or a task consists mostly of one type of trials, e.g., the proportion of incongruent to congruent trial equals $92 / 8 \%$ (as in the first experiment of Costa et al., 2009), then the involvement of the monitoring system should be low and we would not observe any bilingual advantages (Costa et al., 2009). Thus far, the empirical evidence seemed to be consistent with the second hypothesis, since bilinguals' superiority in conflict resolution was always accompanied by the overall RT effect (see Costa et al., 2009, for review). However, this hypothesis seems to be falsified by the present RT data demonstrating bilingual advantage in conflict trials only, and not in the overall response time. Such a pattern of results was obtained despite the fact that the procedure involved an equal number of conflict and non-conflict trials that were mixed within blocks and presented in a random order, which is presumed to engage monitoring system to a great extent (Costa et al., 2009).

Further evidence for the bilingual advantage in conflict resolution was provided by our subsequent study, which used a similar LANT task, but tested different participants (Tao, Marzecová, Taft, Asanowicz \& Wodniecka, 2011). In this study, we found that late Chinese-English bilinguals with a moderate balance in proficiency between two languages also showed higher efficiency in conflict resolution than English monolinguals (in both RT and ERR), without significant group differences in overall performance. In contrast, a group of early but less balanced Chinese-English bilinguals outperformed English monolinguals in overall RT and showed the reduced conflict effect in RT, but not in ERR. Thus, the difference between monolinguals and late bilinguals in Tao et al.'s study was consistent with the current results, whereas the difference between monolinguals and early bilinguals was in line with previous studies (see Costa et al., 2009; Tao et al., 2011, for a review). Taken together, the evidence from both of our studies supports the first hypothesis set out by Costa et al. (2009), according to which bilingualism may modulate functioning of both monitoring and conflict resolution systems in an independent manner. Moreover, these findings suggest that the effects of bilingualism may depend on particular factors of language experience. In the present study results of early and relatively balanced bilinguals closely resembled those obtained by the group of relatively balanced but late bilinguals in Tao et al.'s study. It seems therefore that the balance of proficiency may be more critical than the age of L2 acquisition for the advantage in conflict resolution to emerge.

Although the present study shows no difference between monolinguals and bilinguals in the congruent condition as measured by RT, we have found that bilinguals were slightly more accurate than monolinguals in trials with congruent flankers. Why did monolinguals commit more errors in the simple non-conflict condition? On the one hand, this effect might be interpreted in line with Costa et al. (2009) as a bilingual advantage in monitoring processing. On the other hand, if we consider possible reasons for committing errors in the non-conflict condition, an alternative interpretation seems to be equally plausible. The reported advantage of bilinguals in the 
congruent condition may result from their better ability to focus attention on a task at hand. Studies using behavioral, electrophysiological and imaging methods show that inherent fluctuations and lapses in executive attention can disrupt goal-directed behavior and lead to response errors (Padilla, Wood, Hale \& Knight, 2006; Sylvester, d'Avossa \& Corbetta, 2006; Weissman, Roberts, Visscher \& Woldorff, 2006; West, 1999). This is not only true for conditions in which competition or conflict occurs, but also for easier, non-conflict tasks (see Weissman et al., 2006). While errors in the conflict condition are certainly caused by interference from incongruent flankers, errors in the non-conflict condition seem to result primarily from lapses of attention. It has been shown that attentional lapses are related to fluctuations and lapses of executive control, as well as reduced pre-stimulus activity in the ACC and the PFC regions, which subserve executive control (Padilla et al., 2006; Weissman et al., 2006). Although there is no reason to assume that bilinguals are free from experiencing such fluctuations and lapses of attention, it seems that their more efficient and thus more stable functioning of the executive network may help to avoid such lapses during the pre-trial period, which may consequently allow bilinguals to be more focused on a task at hand.

\section{Alerting effect}

When an alerting cue was presented bilinguals responded considerably faster than monolinguals, whereas in the absence of the cue the same level of performance was observed in both groups. The results corroborate the earlier surprising finding of Costa et al. (2008) and seem to suggest that bilingualism also influences the efficiency of the alerting network. However, it is not clear, which specific factor of the everyday bilingual experience can lead to a more efficient alerting and what mechanism might underlie such effect. It is worth mentioning that in Costa et al.'s (2008) study, the unexpected effect of bilingualism on alerting was in fact larger and more stable than the predicted benefit for conflict resolution. An explanation suggested by Costa et al. (2008) was that a more efficient alerting network might support bilinguals in obtaining and maintaining an alert state, which in turn allows them to efficiently prepare the executive system for monitoring and conflict resolution (2008, pp. 80-81). However, the results of Costa and colleagues as well as the results of the present study do not conform to this hypothesis, because in both studies bilingual advantage in conflict resolution remained at the same level regardless of the presence or absence of the alerting cue.

Two issues should be taken into account when interpreting the alerting effect. First, at least two components contribute to the alerting effect: the tonic and the phasic alertness (Fernandez-Duque \& Posner,
2001). Consequently, in some individuals a larger alerting index may be caused by a difficulty in maintaining alert state in the no cue condition, while in others it may result from more efficient processing of the alert cue and thereby faster responses to targets following the cue (Posner, 2008). For instance, children show a larger alerting effect than adults because of their difficulty in maintaining internal tonic alertness, and their response time is much longer when no alert cue is present (Rueda, Fan, McCandliss, Halparin, Gruber, Lercari \& Posner, 2004). However, larger alerting index may also indicate higher efficiency of phasic alertness (triggered by an alert cue) in achieving the state of readiness to process target stimuli. Second, if an alert cue signals a target with a high temporal validity, there is an additional process involvedan anticipation or temporal orienting that facilitates response preparation and execution (Correa, 2010; Fan, Kolster, Ghajar, Suh, Knight, Sarkar \& McCandliss, 2007; Foxe, Simpson, Ahlfors \& Saron, 2005; Nobre, 2001). In the task used in our study (as well as in the task used by Costa et al., 2008), the SOA (stimulus onset asynchrony) between the alert cue and target was fixed at $500 \mathrm{~ms}$, thus the cue provided precise information about the time when the target will occur. Consequently, the responses in the alerting (center) cue condition were not only faster than in the no cue condition, but were also more accurate, whereas an alerting effect typically leads to faster RT, but with the cost of higher error rate. It seems therefore that the alerting index in the current study reflects effects of response preparation or temporal orienting rather than phasic alerting.

Importantly, the processes of response anticipation or temporal orienting are assumed to be controlled by the domain-general executive network (Fan et al., 2007; Padilla et al., 2006). This notion is supported by a number of imaging studies showing that both response anticipation and conflict resolution engage some common neural regions that are crucial for executive control, primarily the anterior cingulate cortex and the prefrontal cortex (Fan et al., 2007; Fassbender, Foxe \& Garavan, 2006; Liang, Bressler, Ding, Truccolo \& Nakamura, 2002). Neuropsychological studies have also suggested that the prefrontal regions of executive network are involved in the temporal control of the preparation of responses (Triviño, Correa, Arnedo \& Lupiáñez, 2010; Triviño, Arnedo, Lupiáñez, Chirivella \& Correa, 2011). Therefore, it seems plausible that benefit from the alerting cue observed in bilinguals may be accounted for by the enhancement of their executive network, which efficiently subserves the processes of response anticipation or temporal orienting.

\section{Orienting network}

When comparing the efficiency of spatial orienting in bilinguals and monolinguals, no differences were 
observed. Both groups benefited from the valid orienting cue to the same extent, which corroborates previous results (Costa et al., 2008, 2009; Hernández et al., 2010). Also, the two groups did not differ in the efficiency of reorienting to the invalidly cued targets. Therefore we did not confirm our previous results (Tao et al., 2011), which suggested that bilingualism might entail less effective performance in the invalid cue condition, possibly due to stronger inhibition of the reorienting system (occurring when spatial cues are highly predictive; Doricchi, Macci, Silvetti \& Macaluso, 2010; Lasaponara, Chica, Lecce, Lupiáñez \& Doricchi, 2011). Although evidence suggesting that bilingualism may affect attentional orienting was previously reported also by Colzato et al. (2008), there are substantial methodological differences between the experimental tasks used in our and Colzato et al.'s studies. While Colzato et al. (2008) measured exogenous orienting, the LANT taps into endogenous orienting (see Corbetta \& Shulman, 2002; Posner, 1980). Future research should address the issue of endo- and exogenous orienting of spatial attention in bilinguals.

\section{Hemispheric asymmetry}

Another point of our interest was hemispheric asymmetry of attentional networks in bilinguals. As noted in the introduction, Hausmann et al. (2004) suggested that bilingualism may reduce lateralization of non-verbal cognitive functions. In accordance with our previous LANT study (Asanowicz et al., 2012), monolinguals were expected to show a left visual field/right hemisphere advantage in the task conditions that required reorienting of attention and resolution of conflict. Bilinguals, on the other hand, were expected to exhibit reduced lateralization of those processes, in which they were more efficient than monolinguals, in line with the recent claims that bilingualism may affect the functional organization of those cognitive functions that are specifically related to the functioning of bilinguals (e.g. Luk et al., 2010) and with the notion that reduced hemispheric asymmetry is linked with better performance (Boles \& Barth, 2011; Boles et al., 2008).

We found the LVF advantage in the invalid spatial cue condition for the ERR data pooled across both language groups, which replicates previous findings by Asanowicz et al. (2012), Evert, McGlinchey-Berroth, Verfaellie \& Milberg (2003), and Tao et al. (2011). These results presumably reflect right hemisphere specialization in reorienting of attention to relevant events appearing in unattended location (Corbetta \& Shulman, 2002; Shulman \& Corbetta, 2012). Since no difference in the lateralization effect was found between the two groups, we can conclude that bilingualism does not seem to affect the hemispheric asymmetry of attentional reorienting. Crucially, a differential lateralization pattern of the conflict effect was observed in bilinguals when compared to monolinguals. In the non-conflict condition, no asymmetry was observed for either of the groups. In the conflict condition, monolinguals showed a clear LVF advantage, consistent with our previous results (Asanowicz et al., 2012; Tao et al., 2011) and with a number of imaging studies suggesting right hemisphere's superiority in attentional control of response execution (Aron, Robbins \& Poldrack, 2004; Hazeltine, Bunge, Scanlon \& Gabrieli, 2003; Levy \& Wagner, 2011; Milham, Banich, Webb, Barad, Cohen, Wszalek \& Kramer, 2001; for further discussion of this issue see Asanowicz et al., 2012), while bilinguals' accuracy was almost the same in left and right hemifield. It is worth mentioning that a similar pattern of results was previously obtained by means of event-related EEG potentials in a language judgment task by Moreno et al. (2010). The authors reported that resolution of conflict in sentence processing evoked a bilateral pattern of brain's electrical activity in bilingual young adults and left-lateralized activation in monolinguals (see also Park et al., 2012 for an fMRI study with lexical decision task showing reduced lateralization in bilinguals).

How can we, then, explain the reduced lateralization of attentional processes in bilinguals? Recently, Boles and Barth (2011) and Boles et al. (2008) proposed a maturity hypothesis, which describes a mechanism of lateralization of cognitive processes in the course of development. According to the hypothesis, if a mental process is developing early in life, when efficiency of commissural transfer of information is low due to immaturity of the corpus callosum, then the process will be more strongly lateralized. However, a process that is developing longer or later in life (e.g., in middle childhood) should be less lateralized, because then the more mature corpus callosum allows easier and less error-prone spreading of information between the hemispheres, and thus accelerates development of a more bilateral organization of the process (Boles et al., 2008). Crucially, "a process that is distributed across homologous locations between hemispheres may be more efficient than one distributed in fragments within a single hemisphere" (Boles et al., 2008 , p. 136). It seems that adopting the logic proposed by Boles and Barth (2011) and Boles et al. (2008) may lead to a preliminary model of the reduced asymmetry and the enhanced efficiency of executive processes in bilinguals. Assuming that bilinguals constantly engage executive control when using two languages on daily basis, especially during the course of learning and refining their proficiency in both languages, we can hypothesize that the development of executive network in bilingual children is not only more intense than in their monolingual peers, but has also a longer trajectory. If this holds true, bilinguals' executive processes may still be intensively developing 
in a period when callosal maturation is already more advanced, which, according to the maturity hypothesis, should result in a reduced lateralization.

Pursuing the proposed notion further, it seems that a more bilaterally organized system may entail a need for the more effective inter-hemispheric communication. Indeed, on behavioral level, a reduced functional lateralization has been repeatedly observed in individuals with a larger corpus callosum, which is supposed to enhance and facilitate the sharing of information between the hemispheres (Westerhausen \& Hugdahl, 2008; Witelson, 1995; Yazgan, Wexler, Kinsbourne, Peterson \& Leckman, 1995). Interestingly, a recent study using fMRI and diffusion tensor imaging (DTI) showed higher white matter integrity in the corpus callosum in older bilinguals relative to their monolingual age-matched controls (Luk, Bialystok, Craik \& Grady, 2011). Accordingly, Bialystok, Craik \& Luk (2012, p. 245) suggest that because the locus of cognitive control in bilinguals is likely to be localized in bilateral frontal regions, "in order to facilitate information transfer between the hemispheres, it is also possible that prolonged bilingual experience alters anatomical structures", namely the corpus callosum, as was demonstrated by Luk et al. (2011; see also Coggins, Kennedy \& Armstrong, 2004, for similar results).

\section{Concluding remarks}

In conclusion, the present findings provide further support for the hypothesis that bilingualism enhances the efficiency of executive attention. A novel aspect of the results is the increased ability of conflict resolution per $s e$, in the absence of the overall response time advantage, observed in early bilinguals speaking in typologically similar languages (mostly Slovak and Czech). These results complement our other study that showed similar effects in late bilinguals whose languages (Chinese and English) were very distant from each other (Tao et al., 2011), and support the hypothesis suggesting dissociable influence of bilingualism on conflict resolution and monitoring processes (Costa et al., 2009). The current study also showed larger alerting effect in bilinguals, corroborating the finding by Costa et al. (2008). We suggest that the bilingual advantage in alerting effect may in fact reflect bilinguals' enhanced efficiency of executive control, which improves response preparation or temporal orienting when an alert cue provides precise information about a target onset. The third finding of the present study is the reduced LVF advantage of conflict resolution in bilinguals, which implies that bilingual experience may influence the efficiency as well as the functional organization of executive network. We propose a new theoretical approach to the issue of hemispheric asymmetry in bilinguals by adopting the maturity hypothesis, which links reduced lateralization with increased efficiency (Boles \& Barth, 2011; Boles et al., 2008). Taken together, the present results help delineate the boundaries of bilingual impact on different functions of attention and provide further understanding of how bilingualism may influence functional organization of the attentional system.

\section{References}

Abutalebi, J., Annoni, J. M., Zimine, I., Pegna, A. J., Seghier, M. L., Lee-Jahnke, H., Lazeyras, F., Cappa, S. F., \& Khateb, A. (2008). Language control and lexical competition in bilinguals: An event-related MRI study. Cerebral Cortex, 18 (7), 1496-1505.

Abutalebi, J., \& Green, D. W. (2007). Bilingual language production: The neurocognition of language representation and control. Journal of Neurolinguistics, 20 (3), 242-275.

Aron, A. R., Robbins, T. W., \& Poldrack, R. A. (2004). Inhibition and the right inferior frontal cortex. Trends in Cognitive Sciences, 8 (4), 170-177.

Asanowicz, D., Marzecová, A., Jaśkowski, P., \& Wolski, P. (2012). Hemispheric asymmetry in the efficiency of attentional networks. Brain and Cognition, 79 (2), 117128.

Bialystok, E. (2005). Consequences of bilingualism for cognitive development. In J. R. Kroll \& A. M. B. de Groot (eds.), Handbook of bilingualism: Psycholinguistic approaches, pp. 417-432. Oxford: Oxford University Press.

Bialystok, E., Craik, F. I. M., Green, D. W., \& Gollan, T. H. (2009). Bilingual minds. Psychological Science in the Public Interest, 10 (3), 89-129.

Bialystok, E., Craik, F. I., Klein, R., \& Viswanathan, M. (2004). Bilingualism, aging, and cognitive control: Evidence from the Simon task. Psychology and Aging, 19 (2), 290-303.

Bialystok, E., Craik, F. I., \& Luk, G. (2012). Bilingualism: Consequences for mind and brain. Trends in Cognitive Sciences, 16 (4), 240-250.

Bialystok, E., Martin, M. M., \& Viswanathan, M. (2005). Bilingualism across the lifespan: The rise and fall of inhibitory control. International Journal of Bilingualism, 9 (1), 103-119.

Boles, D. B., \& Barth, J. M. (2011). "Does degree of asymmetry relate to performance?": A critical review. Brain and Cognition, 76 (1), 1-4.

Boles, D. B., Barth, J. M., \& Merrill, E. C. (2008). Asymmetry and performance: Toward a neurodevelopmental theory. Brain and Cognition, 66 (2), 124-139.

Callejas, A., Lupiáñez, J., \& Tudela, P. (2004). The three attentional networks: On their independence and interactions. Brain and Cognition, 54 (3), 225-227.

Carrasco, M., Ling, S., \& Read, S. (2004). Attention alters appearance. Nature Neuroscience, 7 (3), 308-313.

Coggins, P. E., Kennedy, T. J., \& Armstrong, T. A. (2004). Bilingual corpus callosum variability. Brain and Language, 89 (1), 69-75.

Colzato, L. S., Bajo, M. T., van den Wildenberg, W., Paolieri, D., Nieuwenhuis, S., La Heij, W., \& Hommel, B. (2008). How does bilingualism improve executive control? A comparison of active and reactive inhibition mechanisms. 
Journal of Experimental Psychology: Learning, Memory, and Cognition, 34 (2), 302-312.

Corbetta, M., \& Shulman, G. L. (2002). Control of goal-directed and stimulus-driven attention in the brain. Nature Reviews Neuroscience, 3 (3), 201-215.

Correa, A. (2010). Enhancing behavioural performance by visual temporal orienting. In A. C. Nobre \& J. T. Coull (eds.), Attention and time, pp. 357-370. Oxford: Oxford University Press.

Costa, A., Hernández, M., Costa-Faidella, J., \& SebastiánGallés, N. (2009). On the bilingual advantage in conflict processing: Now you see it, now you don't. Cognition, 113 (2), 135-149.

Costa, A., Hernández, M., \& Sebastián-Gallés, N. (2008). Bilingualism aids conflict resolution: Evidence from the ANT task. Cognition, 106 (1), 59-86.

Dehaene, S., Dupoux, E., Mehler, J., Cohen, L., Paulesu, E., Perani, D., Van de Moortele, P. F., Lehéricy, S., \& Le Bihan, D. (1997). Anatomical variability in the cortical representation of first and second language. Neuroreport, 8 (17), 3809

Dien, J. (2009). A tale of two recognition systems: Implications of the fusiform face area and the visual word form area for lateralized object recognition models. Neuropsychologia, 47 (1), 1-16.

Doricchi, F., Macci, E., Silvetti, M., \& Macaluso, E. (2010). Neural correlates of the spatial and expectancy components of endogenous and stimulus-driven orienting of attention in the Posner task. Cerebral Cortex, 20, 1574-1585.

Engle, R., \& Kane, M. (2004). Executive attention, working memory capacity, and a two- factor theory of cognitive control. In B. Ross (ed.), The psychology of learning and motivation (vol. 44): Advances in research and theory, pp. 145-199. New York: Elsevier.

Eriksen, B. A., \& Eriksen, C. W. (1974). Effects of noise letters upon the identification of a target letter in a nonsearch task. Perception \& Psychophysics, 16 (1), 143-149.

Evert, D. L., McGlinchey-Berroth, R., Verfaellie, M., \& Milberg, W. P. (2003). Hemispheric asymmetries for selective attention apparent only with increased task demands in healthy participants. Brain and Cognition, 53 (1), 34-41.

Fan, J., Gu, X., Guise, K. G., Liu, X., Fossella, J., Wang, H., \& Posner, M. I. (2009). Testing the behavioral interaction and integration of attentional networks. Brain and Cognition, 70 (2), 209-220.

Fan, J., Kolster, R., Ghajar, J., Suh, M., Knight, R. T., Sarkar, R., \& McCandliss, B. D. (2007). Response anticipation and response conflict: An event-related potential and functional magnetic resonance imaging study. The Journal of Neuroscience: The Official Journal of the Society for Neuroscience, 27 (9), 2272-2282.

Fan, J., McCandliss, B. D., Fossella, J., Flombaum, J. I., \& Posner, M. I. (2005). The activation of attentional networks. Neuroimage, 26 (2), 471-479.

Fan, J., McCandliss, B. D., Sommer, T., Raz, A., \& Posner, M. I. (2002). Testing the efficiency and independence of attentional networks. Journal of Cognitive Neuroscience, 14 (3), 340-347.

Fassbender, C., Foxe, J. J., \& Garavan, H. (2006). Mapping the functional anatomy of task preparation: Priming task- appropriate brain networks. Human Brain Mapping, 27 (10), 819-827.

Fernandez-Duque, D., \& Posner, M. I. (2001). Brain imaging of attentional networks in normal and pathological states. Journal of Clinical and Experimental Neuropsychology, 23 (1), 74-93.

Forster, K. I., \& Forster, J. C. (2003). DMDX: A windows display program with millisecond accuracy. Behavior Research Methods, Instruments, \& Computers, 35 (1), 116124.

Foxe, J. J., Simpson, G. V., Ahlfors, S. P., \& Saron, C. D. (2005). Biasing the brain's attentional set: I. Cue driven deployments of intersensory selective attention. Experimental Brain Research, 166 (3-4), 370-392.

Gainotti, G. (2007). Different patterns of famous people recognition disorders in patients with right and left anterior temporal lesions: A systematic review. Neuropsychologia, 45 (8), 1591-1607.

Garbin, G., Sanjuan, A., Forn, C., Bustamante, J. C., RodriguezPujadas, A., Belloch, V., Hern[á]ndez, M., Costa, A., \& Ávila, C. (2010). Bridging language and attention: Brain basis of the impact of bilingualism on cognitive control. Neuroimage, 53 (4), 1272-1278.

Green, D. W. (1998). Mental control of the bilingual lexicosemantic system. Bilingualism: Language and Cognition, $1,67-81$.

Greene, D. J., Barnea, A., Herzberg, K., Rassis, A., Neta, M., Raz, A., \& Zaidel, E. (2008). Measuring attention in the hemispheres: The lateralized attention network test (LANT). Brain and Cognition, 66 (1), 21-31.

Hausmann, M., Durmusoglu, G., Yazgan, Y., \& Güntürkün, O. (2004). Evidence for reduced hemispheric asymmetries in non-verbal functions in bilinguals. Journal of Neurolinguistics, 17 (4), 285-299.

Hazeltine, E., Bunge, S. A., Scanlon, M. D., \& Gabrieli, J. D. (2003). Material-dependent and material-independent selection processes in the frontal and parietal lobes: An event-related fMRI investigation of response competition. Neuropsychologia, 41 (9), 1208-1217.

Heilman, K. M. (1995). Attentional asymmetries. In R. J. Davidson \& K. Hugdahl (eds.), Brain asymmetry, pp. 217 234. Cambridge, MA: MIT Press.

Hernández, M., Costa, A., Fuentes, L. J., Vivas, A. B., \& Sebastián-Gallés, N. (2010). The impact of bilingualism on the executive control and orienting networks of attention. Bilingualism: Language and Cognition, 13, 315-325.

Hilchey, M. D., \& Klein, R. M. (2011). Are there bilingual advantages on nonlinguistic interference tasks? Implications for the plasticity of executive control processes. Psychonomic Bulletin \& Review, 18 (4), 625658.

Hull, R., \& Vaid, J. (2006). Laterality and language experience. Laterality, 11 (5), 436-464.

Hull, R., \& Vaid, J. (2007). Bilingual language lateralization: A meta-analytic tale of two hemispheres. Neuropsychologia, 45 (9), 1987-2008.

Kane, M. J., Hambrick, D. Z., Tuholski, S. W., Wilhelm, O., Payne, T. W., \& Engle, R. W. (2004). The generality of working memory capacity: A latent-variable approach to verbal and visuospatial memory span and reasoning. 
Journal of Experimental Psychology: General, 133 (2), 189-217.

Kousaie, S., \& Phillips, N. A. (2011). Ageing and bilingualism: Absence of a "bilingual advantage" in Stroop interference in a nonimmigrant sample. The Quarterly Journal of Experimental Psychology, 65 (2), 356-369.

Kousaie, S., \& Phillips, N. A. (2012). Conflict monitoring and resolution: Are two languages better than one? Evidence from reaction time and event-related brain potentials. Brain Research, 1446, 71-90.

Lasaponara, S., Chica, A. B., Lecce, F., Lupiáñez, J., \& Doricchi, F. (2011). ERP evidence for selective drop in attentional costs in uncertain environments: Challenging a purely premotor account of covert orienting of attention. Neuropsychologia, 49 (9), 2648-2657.

Levy, B. J., \& Wagner, A. D. (2011). Cognitive control and right ventrolateral prefrontal cortex: Reflexive reorienting, motor inhibition, and action updating. Annals of the New York Academy of Sciences, 1224, 40-62.

Li, P., Sepanski, S. A. A., \& Zhao, X. A. W. (2006). Language History Questionnaire: A web-based interface for bilingual research. Behavior Research Methods, 38 (2), 202-210.

Liang, H., Bressler, S. L., Ding, M., Truccolo, W. A., \& Nakamura, R. (2002). Synchronized activity in prefrontal cortex during anticipation of visuomotor processing. Neuroreport, 13 (16), 2011-2015.

Luk, G., Anderson, J. A., Craik, F. I., Grady, C., \& Bialystok, E. (2010). Distinct neural correlates for two types of inhibition in bilinguals: Response inhibition versus interference suppression. Brain and Cognition, 74 (3), 347-357.

Luk, G., Bialystok, E., Craik, F. I., \& Grady, C. L. (2011). Lifelong bilingualism maintains white matter integrity in older adults. The Journal of Neuroscience: The Official Journal of the Society for Neuroscience, 31 (46), 1680816813.

Macleod, J. W., Lawrence, M. A., McConnell, M. M., Eskes, G. A., Klein, R. M., \& Shore, D. I. (2010). Appraising the ANT: Psychometric and theoretical considerations of the Attention Network Test. Neuropsychology, 24 (5), 637-651.

Mesulam, M. M. (1999). Spatial attention and neglect: Parietal, frontal and cingulate contributions to the mental representation and attentional targeting of salient extrapersonal events. Philosophical Transactions of the Royal Society of London. Series B, Biological Sciences, 354 (1387), 1325-1346.

Milham, M. P., Banich, M. T., Webb, A., Barad, V., Cohen, N. J., Wszalek, T., \& Kramer, A. F. (2001). The relative involvement of anterior cingulate and prefrontal cortex in attentional control depends on nature of conflict. Cognitive Brain Research, 12 (3), 467-473.

Moreno, S., Bialystok, E., Wodniecka, Z., \& Alain, C. (2010). Conflict resolution in sentence processing by bilinguals. Journal of Neurolinguistics, 23 (6), 564-579.

Morton, J. B., \& Harper, S. N. (2007). What did Simon say? Revisiting the bilingual advantage. Developmental Science, 10 (6), 719-726.

Niogi, S., Mukherjee, P., Ghajar, J., \& McCandliss, B. D. (2010). Individual differences in distinct components of attention are linked to anatomical variations in distinct white matter tracts. Frontiers in Neuroanatomy, 4 (2), 1-12.
Nobre, A. C. (2001). Orienting attention to instants in time. Neuropsychologia, 39 (12), 1317-1328.

Padilla, M. L., Wood, R. A., Hale, L. A., \& Knight, R. T. (2006). Lapses in a prefrontal-extrastriate preparatory attention network predict mistakes. Journal of Cognitive Neuroscience, 18 (9), 1477-1487.

Paradis, M. (1995). Another sighting of differential language laterality in multilinguals, this time in Loch Tok Pisin: Comments on Wuillemin, Richardson \& Lynch (1994). Brain and Language, 49, 173-186.

Paradis, M. (2003). The bilingual Loch Ness monster raises its non-asymmetric head again - or, why bother with such cumbersome notions as validity and reliability? Comments on Evans et al. (2000). Brain and Language, 87 (3), 441448.

Paradis, M. (2008). Bilingual laterality: Unfounded claim of validity. A comment on Hull \& Vaid (2007). Neuropsychologia, 46 (5), 1588-1590.

Park, H. R., Badzakova-Trajkov, G., \& Waldie, K. E. (2012). Language lateralisation in late proficient bilinguals: A lexical decision fMRI study. Neuropsychologia, 50 (5), 688-695.

Peng, G., \& Wang, W. S.-Y. (2010). Hemisphere lateralization is influenced by bilingual status and composition of words. Neuropsychologia, 49 (7), 1981-1986.

Posner, M. I. (1980). Orienting of attention. Quarterly Journal of Experimental Psychology, 32 (1), 3-25.

Posner, M. I. (2008). Measuring alertness. Annals of the New York Academy of Sciences, 1129, 193-199.

Posner, M. I., \& Boies, S. J. (1971). Components of attention. Psychological Review, 78 (5), 391-408.

Posner, M. I., \& Petersen, S. E. (1990). The attention system of the human brain. Annual Review of Neuroscience, 13, 25-42.

Posner, M. I., \& Rothbart, M. K. (2007). Research on attention networks as a model for the integration of psychological science. Annual Review of Psychology, 58, 1-23.

Prior, A., \& MacWhinney, B. (2010). A bilingual advantage in task switching. Bilingualism: Language and Cognition, 13 (2), 253-262.

Raven, J., Raven, J. C., \& Court, J. H. (1998). Manual for Raven's Advanced Progressive matrices (1998 edition). Oxford: Oxford Psychologists Press.

Rueda, M. R., Fan, J., McCandliss, B. D., Halparin, J. D., Gruber, D. B., Lercari, L. P., \& Posner, M. I. (2004). Development of attentional networks in childhood. Neuropsychologia, 42 (8), 1029-1040.

Shulman, G. L., \& Corbetta, M. (2012). Two attentional networks: Identification and function within a larger cognitive architecture. In M. I. Posner (ed.), Cognitive neuroscience of attention (2nd edn.), pp. 113-128. New York: The Guilford Press.

Sylvester, C. M., d'Avossa, G., \& Corbetta, M. (2006). Models of human visual attention should consider trial-by-trial variability in preparatory neural signals. Neural Networks, 19 (9), 1447-1449.

Tao, L., Marzecová, A., Taft, M., Asanowicz, D., \& Wodniecka, Z. (2011). The efficiency of attentional networks in early and late bilinguals: The role of age of acquisition. Frontiers in Psychology, 2 (123), 1-19. 
Treccani, B., Argyri, E., Sorace, A., \& Sala, S. D. (2009). Spatial negative priming in bilingualism. Psychonomic Bulletin \& Review, 16 (2), 320-327.

Triviño, M., Arnedo, M., Lupiáñez, J., Chirivella, J., \& Correa, A. (2011). Rhythms can overcome temporal orienting deficit after right frontal damage. Neuropsychologia, 49 (14), 3917-3930.

Triviño, M., Correa, A., Arnedo, M., \& Lupiáñez, J. (2010). Temporal orienting deficit after prefrontal damage. Brain, 133 (4), 1173-1185.

van Heuven, W. J., Schriefers, H., Dijkstra, T., \& Hagoort, P. (2008). Language conflict in the bilingual brain. Cerebral Cortex, 18 (11), 2706-2716.

Weissman, D. H., Roberts, K. C., Visscher, K. M., \& Woldorff, M. G. (2006). The neural bases of momentary lapses in attention. Nature Neuroscience, 9 (7), 971-978.

West, R. (1999). Age differences in lapses of intention in the Stroop task. The Journals of Gerontology. Series B: Psychological Sciences and Social Sciences, 54B (1), P34P43.
Westerhausen, R., \& Hugdahl, K. (2008). The corpus callosum in dichotic listening studies of hemispheric asymmetry: A review of clinical and experimental evidence. Neuroscience and Biobehavioral Reviews, 32 (5), 1044-1054.

Westlye, L. T., Grydeland, H., Walhovd, K. B., \& Fjell, A. M. (2010). Associations between regional cortical thickness and attentional networks as measured by the attention network test. Cerebral Cortex, 21 (2), 345-356.

Witelson, S. F. (1995). Neuroanatomical bases of hemispheric functional specialization in the human brain: Possible developmental factors. In F. L. Kitterle (ed.), Hemispheric communication: Mechanisms and models, pp. 61-84. Hillsdale, NJ: Lawrence Erlbaum.

Yazgan, M. Y., Wexler, B. E., Kinsbourne, M., Peterson, B., \& Leckman, J. F. (1995). Functional significance of individual variations in callosal area. Neuropsychologia, 33 (6), 769 779.

Ye, Z., \& Zhou, X. (2009). Executive control in language processing. Neuroscience and Biobehavioral Reviews, 33 (8), 1168-1177. 